where the $\alpha$ 's and $\beta^{\prime}$ s are now functions of $\mathbf{D}^{\prime} \cdot \mathbf{D}^{\prime}, \mathbf{B}^{\prime} \cdot \mathbf{B}^{\prime},\left(\mathbf{D}^{\prime} \cdot \mathbf{B}^{\prime}\right)^{2}$ and $t$ and depend on $\varphi$ and $\psi$. These equations indicate the possibility of both transverse electric and magnetic effects.

Acknowledgment. The results presented in this paper were obtained in the course of research supported by a contract of the Advanced Research Projects Agency with Brown University.

\title{
REFERENCES
}

1. A. C. Pipkin and R. S. Rivlin, J. Math. Phys. 1, 542 (1960)

2. A. S. Wineman and A. C. Pipkin, J. Rat'l Mech. Anal. 12, 420 (1963)

\section{Corrections to the paper \\ FINITE PURE BENDING OF CIRCULAR CYLINDRICAL TUBES}

Quarterly of Applied Mathematics, XX, 305-319 (1963)

BY E. REISSNER AND H. J. WEINITSCHKE

(Massachusetts Institute of Technology)

The numerical values in Table 2 of this paper should be corrected in such a way that Table 2 now reads

\begin{tabular}{c|c|c|c|c|} 
& 2 terms & 3 terms & 4 terms & $\begin{array}{c}\text { numerical } \\
\text { solution }\end{array}$ \\
\hline$\alpha_{c}$ & 1.633 & 1.439 & 1.541 & 1.66 \\
$m_{c}$ & 1.089 & 1.002 & 1.034 & 1.06
\end{tabular}

The above values of $\alpha_{c}$ and $m_{c}$ are in agreement with the corresponding values in Figure 2 of the original paper. 